Dermatology 2009;218:84-85

DOI: $\underline{10.1159 / 000174038}$

\section{Cytomegalovirus Colitis in a Patient Treated with Efalizumab}

Anne Caudron ${ }^{\mathrm{a}}$, Catherine Lok ${ }^{\mathrm{a}}$, Angèle Clabaut ${ }^{\mathrm{a}}$, Julien Desblache ${ }^{\mathrm{a}}$, Bertrand Heyman ${ }^{\mathrm{b}}$, Valérie Viseux ${ }^{\mathrm{a}}$

a Dermatology Service, Amiens University Medical Center, South Hospital, Amiens, and ${ }^{b}$ Gastroenterology Service, Corbie Hospital Center, Corbie, France

Key Words

Cytomegalovirus colitis $\cdot$ Psoriasis $\cdot$ Efalizumab

\section{Case Report}

A 78-year-old woman had suffered from psoriasis since she was 16 years old. The limbs, a large part of the trunk and the buttocks were concerned. She received multiple topical treatments, PUVA therapy, acitretin, then methotrexate for 10 years. However, a skin relapse and a psoriatic arthritis were observed, and a treatment with etanercept (25 mg twice per week) was started. Three months later, the treatment was withdrawn due to lack of efficacy. Efalizumab was introduced ( $0.80 \mathrm{ml}$ per week), and clinical efficiency was quickly observed, without adverse reaction. After 5 months of treatment, abdominal pain and acute watery profuse diarrhea, without blood or mucus, occurred. The patient was hospitalized, and laboratory investigations showed lymphocytosis of $2,516 \cdot \mathrm{mm}^{-3}$ (normal: $1,500-3,500$ ) and a C-reactive protein of $35 \mathrm{mg} \cdot \mathrm{l}^{-1}$ (normal: $<5$ ) without leukocytosis; HIV serology was negative. Bacterial, mycological and parasitological stool examinations were negative or not significant. Clostridium difficile toxin was not detected. A significant increase in cytomegalovirus $(\mathrm{CMV}) \mathrm{IgM}$ was detected $\left[<0.9 \mathrm{IU} \cdot \mathrm{ml}^{-1}\right.$ on the first day of hospitalization; IgG: $3.90 \mathrm{IU} \cdot \mathrm{ml}^{-1}$; IgM: $1.60 \mathrm{IU} \cdot \mathrm{ml}^{-1}$ 2 weeks later with the EIA-Sorin technique (positive result between 1.2 and $\left.7 \mathrm{IU} \cdot \mathrm{ml}^{-1}\right)$ ]. The level of IgG anti-CMV avidity was high, $>0.95$ (infection of more than 3 months if $>0.3$ ). Colonoscopy showed extensive acute inflammatory colitis and fibrinous abscess, without pseudomembrane. Mucosal biopsy showed an inflammatory infiltrate, with cytomegalic inclusions. CMV immunostaining was positive. Herpes immunostaining was negative. The patient was treated with intravenous gancyclovir for 10 days, then valgancyclovir (450 mg twice per day) for 2 weeks. Diarrhea resolved completely within 2 weeks. Efalizumab was definitively stopped.

\section{Discussion}

Efalizumab is a recombinant humanized monoclonal antibody used for chronic plaque psoriasis refractory to other systemic treatments (methotrexate, ciclosporin, PUVA therapy). The most frequent efalizumab side effects are influenza syndrome, infections, pruritus and arthritis [1-4]. Malignancies are not increased in patients treated with efalizumab [5]. A study of the clinical trial experience shows that efalizumab is not associated with an increased risk for infection, and $1.1 \%$ of efalizumab-treated patients are hospitalized for severe infections [6]. However, a recent case of visceral leishmaniasis infection has been reported underscoring that visceral leishmaniasis should be taken into account during efalizumab treatment, at least for patients living in endemic areas [7]. A disseminated eruptive giant molluscum contagiosum has been reported recently under efalizumab treatment too [8].

Watery diarrhea, tenesmus, hematochezia and abdominal pain are present in CMV colitis. The diagnosis is based on histological examination of colic biopsy, positive CMV antigen and high CMV IgM titer in peripheral blood samples, as in our patient. Reactivation of CMV was considered since CMV serology had been positive for IgG and negative for IgM at the beginning of the hospitalization. During the second week of infection, the IgM level was positive at $1.60 \mathrm{IU} \cdot \mathrm{ml}^{-1}$. Moreover, the level of IgG anti-CMV avidity was high $(>0.95)$ which is in favor of an infection being present for more than 3 months. Fast improvement with systemic gancyclovir is another criterion for the diagnosis of CMV colitis.

In Gottlieb et al. [9], CMV seroconversion in 51 patients treated with efalizumab has been evaluated. Subjects with negative CMV IgM serology at the beginning remained negative at the end of the study. We report the first case of CMV colitis in a patient treated with efalizumab. In patients treated with efalizumab, diarrheas are reported (6\% of patients) but poorly documented [4]. The incidence of CMV infection may be underestimated. Differential diagnoses such as Salmonella, Shigella, Clostridium or cryptococcal infections have been eliminated with stool cultures. Colonoscopy with biopsy should be proposed to patients who complain of persistent or recurring diarrhea.

Efalizumab is a specific antibody to the CD11a of lymphocyte function-associated antigen type 1 (LFA-1). Infections are induced by altered function of T-cell lymphocytes, blocking LFA-1 (a cell adhesion molecule) on T cells, and this is not associated with lymphocyte depletion [6]. T cells play a decisive role rather than B cells in CMV infection. On the surface of CMV-infected cells, there is an upregulation of ICAM-1. LFA-1 is the ligand of ICAM-1 on leukocytes, which accompany lymphocyte activation

\section{KARGER}

(C) 2008 S. Karger AG, Basel

Fax +41613061234 E-Mail karger@karger.ch www.karger.com 
[10]. Efalizumab, blocking LFA-1, does not prevent lymphocyte activation, and induces a decrease in the patient's immune defense against CMV infection and probably the development of a symptomatic infection. Immunosuppression of T-cell lymphocytes induced by this anti-CD11a antibody is suspected in the reactivation of this severe CMV infection. A case of multiple eruptive dermatofibromas occurring during efalizumab treatment suggests an inhibition of downregulatory $\mathrm{T}$ cells, multiple eruptive dermatofibromas being suspected to be secondary to a putative pathogen [11].

For the other biological therapy, there is a recent case report of CMV colitis in a patient with Behçet's disease receiving infliximab: increased TNF production in response to CMV infection displays anti-CMV activity in vitro, and recombinant TNF- $\alpha$ possesses anti-CMV activity [12]. There is no case of CMV infection reported with etanercept treatment. CMV colitis with azathioprine or mycophenolate mofetil has been reported during the treatment of chronic inflammatory diseases $[13,14]$. CMV infections have been described with cyclophosphamide and methotrexate too (pneumonia, hepatitis) [13]. There is also a decrease in T-cell responsiveness for patients under immunosuppressive or immunomodulatory treatment, which might explain the risk of intracellular infection like CMV colitis [15].

To our knowledge, this is the first case of CMV colitis under efalizumab treatment in a patient with a diagnosis of psoriasis.

\section{References}

1 Technical file of Raptiva (efalizumab). San Francisco, Gentech, 2005.

-2 Rivas-Rodriguez R, Romero-Alonso MM, Gabella-Bazarot E, SanchezGomez E: Efalizumab-induced aseptic meningitis. Farm Hosp 2007;31: $70-71$.

3 Descamps V: Efalizumab: Raptiva ${ }^{\circledR}$. Ann Dermatol Venereol 2007;134: 982-987.

4 Scheinfeld N: Efalizumab: a review of events reported during clinical trials and side effects. Expert Opin Drug Saf 2006;5:197-209.

5 Leonardi CL, Toth D, Cather JC, Langley RG, Werther W, Compton P, Kwon P, et al: A review of malignancies observed during efalizumab (Raptiva) clinical trials for plaque psoriasis. Dermatology 2006;213 204-214.
-6 Langley RG, Carey WP, Rafal ES, Tyring SK, Caro I, Wang X, Wetherill $\mathrm{G}$, Gordon KB: Incidence of infection during efalizumab therapy for psoriasis: analysis of the clinical trial experience. Clin Ther 2005;27: 1317-1328.

7 Balato A, Balato N, Patruno C, Gallo L, Ayala F: Visceral leishmaniasis infection in a patient with psoriasis treated with efalizumab. Dermatology 2008;217:360-361.

8 Weisenseel P, Kuznetsov AV, Flaig M, Prinz JC: Disseminated eruptive giant mollusca contagiosa in an adult psoriasis patient during efalizumab therapy. Dermatology 2008;217:85-86.

9 Gottlieb AB, Miller B, Lowe N, et al: Subcutaneously administered efalizumab (anti-CD11a) improves signs and symptoms of moderate to severe plaque psoriasis. J Cutan Med Surg 2003;7:198-207.

10 Grundy JE, Pahal GS, Akbar AN: Increased adherence of CD2 peripheral blood lymphocytes to cytomegalovirus-infected fibroblasts is blocked by anti-LFA-3 antibody. Immunology 1993;78:413-420.

-11 Santos-Juanes J, Coto-Segura P, Mallo S, Galache C, Soto J: Multiple eruptive dermatofibromas in a patient receiving efalizumab. Dermatology 2008;216:363.

12 Sari I, Birlik M, Gonen C, Akar S, Gurel D, Onen F, Akkoc N: Cytomegalovirus colitis in a patient with Behçet's disease receiving tumor necrosis factor alpha inhibitory treatment. World J Gastroenterol 2008; 14:2912-2914.

13 Tnani N, Massoumi A, Lortholary O, Soussan P, Prinseau J, Baglin A, Hanslik T: Management of cytomegalovirus infections in patients treated with immunosuppressive drugs for chronic inflammatory diseases. Rev Med Int 2008;29:305-310.

14 Helbling D, Breitbach TH, Krause M: Disseminated cytomegalovirus infection in Crohn's disease following anti-tumour necrosis factor therapy. Eur J Gastroenterol Hepatol 2002;14:1393-1395.

15 Carter D, Olchovsky D, Pokroy R, Ezra D: Cytomegalovirus-associated colitis causing diarrhea in an immunocompetent patient. World J Gastroenterol 2006;12:6898-6899.

\section{Anne Caudron}

Dermatology Service, Amiens University Medical Center

South Hospital

FR-80054 Amiens Cedex 1 (France)

Tel. +33 322455 669, Fax +33 322456072

E-Mail annecaudron@aol.com 